\title{
Sobre a comunicação nas grandes cidades
}

\author{
Mabel Piccini \\ Departamento de Educación y Comunicación, Universidad \\ Autónoma Metropolitana-Xochimilco
}

\section{Resumo}

Este artigo examina as transformações culturais do final do século XX a partir de uma análise dos espaços urbanos e sua íntima relação com os dispositivos audiovisuais. Neste sentido, define o surgimento de novos cenários: mudanças nos estilos de vida, na percepção do tempo e do espaço e nos usos da cidade. Do mesmo modo, descreve a emergência de diferentes regimes de visibilidade e enunciação e a construção de lugares híbridos - sem filiação "territorial" - através das tecnologias e dos relatos fundados na primazia da imagem e da velocidade.

Palavras-chave: espaço público, estilo, redes audiovisuais, cidades.

\begin{abstract}
This article examines the cultural changes at the end of the XXth century, focusing the urban spaces and its narrow relationship with audiovisual apparatus. In this sense, it stablishes the emergence of new sceneries: changes in life-style, in the perceptions of time and space, and in the uses of the city. In the same way, it describes the emergence of distinct courses of visibility and expression, and the building of hibrid places - without "territorial" affiliation - through technologies and reports based on the importance of the image and the velocity.

Key words: public space, style, audiovisual networks, cities.
\end{abstract}




\section{Comunidades abstratas}

"O poder político do Estado é apenas secundariamente o poder organizado de uma classe para a opressão de outra; no sentido mais material é polis, polícia, isto é, rede de comunicações." (Paul Virilio, Vitesse et Politique).

Quero situar o problema das tecnologias culturais, e o conjunto de redes audiovisuais em geral, em um campo em que se entrecruzam diferentes dimensões da vida social na atualidade. As culturas da imagem representam um lugar excepcional para compreender alguns dos fenômenos mais significativos das políticas e das formações simbólicas do final do século. No entanto, esse lugar que podemos lhe atribuir não é um lugar próprio ou isolado. É parte de uma cadeia de situações - sítios onde os problemas se materializam e se revelam - que parecem definir, em boa medida, as alternativas e o rumo que adotam as sociedades de nossa época.

Deste ponto de vista, as redes audiovisuais e os terminais eletrônicos fazem parte de um processo que poderíamos descrever como a proliferação do urbano sobre o tecido social; o urbano entendido, segundo Françoise Choay ${ }^{1}$, em seu caráter de sistema operatório que se desenvolve em todos os lugares: nas cidades e no campo, nas vilas e nos bairros, a partir de redes materiais e imateriais e de um conjunto de objetos técnicos que põem em circulação um mundo de imagens e informações que transformam os vínculos que as sociedades mantêm com o espaço, com o tempo e com os indivíduos. Esse avanço do urbano sobre os demais espaços geográficos, sociais e simbólicos, começa a redefinir os limites e a própria materialidade das comunidades, as quais, sustenta Choay, não se fundam mais na proximidade nem na densidade demográfica local. Transportes e telecomunicações nos envolvem em relações cada vez mais numerosas e diversas. Agora integrantes de coletividades abstratas, as implantações espaciais não mais se apresentam nem coincidem com a estabilidade na duração².

\footnotetext{
${ }^{1}$ Citado por ROMAN, 1994, p. 6.

${ }^{2}$ Sem dúvida, é necessário esclarecer que a proliferação do urbano assim entendido é um fenômeno que se pode perceber em toda a sua amplitude em sociedades pós-industriais. De todo modo, com outros ritmos de expansão e outras repercussões, esses processos de urbanização estão presentes ou em vias de desenvolvimento em nossos países.
} 
Já existe uma vasta literatura que situa alguns dos problemas que redefinem as relações sociais, sobretudo em sociedades pós-industriais, a partir desse avanço de técnicas e tecnologias, assim como dos modernos estilos de urbanização e do crescimento acelerado das cidades, dos sistemas de alta velocidade e da proliferação de novos objetos culturais entre híbridos e transnacionais. Entre outros indícios, costumam-se mencionar, com metáforas de certa intensidade, "o desmoronamento do social" e da vida pública, o florescimento do individualismo e o retorno à vida privada, o predomínio de lógicas de supressão do espaço e de "aceleração" dos tempos históricos, a proliferação dos espaços do anonimato e, finalmente, o triunfo da comunicação à distância como novo vínculo com o mundo.

De qualquer modo, qualquer que seja o ângulo a partir do qual se adote um ponto de vista, existe uma certa coincidência em um aspecto que nos parece essencial: assistiríamos a uma crise do que tradicionalmente se entendeu por vida coletiva, sobretudo nas grandes cidades, crise de uma forma de sociabilidade ligada às relações no espaço público e às formas instituídas da comunicação social, o intercâmbio político e a ação política em sua máxima latitude. Tudo isso leva também a recolocar a questão das identidades individuais e coletivas, porque se a identidade dos grupos, por diversas que sejam suas origens, depende do dispositivo espacial que os funda e os reúne, as novas configurações urbanas e os dispositivos de comunicação planetária, ao questionar a estabilidade do território, colocam, por sua vez, novos problemas relativos a uma idéia e a um sentimento de comunidade e pertencimento.

Sobre esses aspectos, que são considerações relativas a sociedades do capitalismo tardio, é preciso estabelecer alguns contrastes e diferenças que se apresentam nas sociedades urbanas periféricas. Embora com outros ritmos e ressonâncias, poderíamos adiantar que algumas das novas sintaxes das urbes do primeiro mundo estão em certa relação com nossas cidades. Tratarei de aproximarme dessas semelhanças que marcam, por sua vez, as distâncias com nossos espaços urbanos. 


\section{Urbanização e marginalidade}

México, Distrito Federal: megalópole? Coletividade abstrata ou cidade multicultural? Uma trans-cidade, ou como dizem alguns, uma pós-cidade? A última cidade tal como a designam os poetas desse espaço, embora não admitam totalmente a idéia do apocalipse?

Desde a tradição consagrada pelos conquistadores hispânicos, a cidade é superposição de poderes que se implantam com violência sobre os existentes para produzir uma realidade nova e erradicar, diante das regularidades previstas, as "irregularidades" da sociedade dos colonizados: a catedral barroca dos conquistadores sobre as pirâmides antigas dos conquistados; a cidade colonial, no presente, junto aos edifícios art-déco de princípios de século e, já no ocaso da centúria, as catedrais de vidro do capital financeiro; as luxuosas residências dos novos poderosos, mansões cercadas por grades de ferro ao lado das favelas da marginalidade. Este traçado contrastante é o que leva Peter Ward a dizer que a Cidade do México é um palimpsesto das lutas anteriores e, poderíamos acrescentar, das atuais (WARD, 1990). Porque, com efeito, a ampliação dos conflitos e contradições, a extensa trama de contrastes que hoje exibe a Cidade do México, continua sendo expressão de variadas lutas que, embora diferentes das anteriores, manifestam, por um lado, o multiculturalismo e, por outro, como sua sombra, os abismos da desigualdade e a diferença de oportunidades entre os diferentes setores sociais. Uns no cume, outros no desenraizamento urbano.

O crescimento acelerado e anárquico das últimas décadas produziu toda sorte de deslocamentos das relações sociais. O mapa é a cidade mosaico onde, junto com uma industrialização selvagem, e em boa medida por essa razão, misturam-se estilos de convivência, mesclas de culturas, populações transplantadas e também disparidades insuperáveis de níveis econômicos e fronteiras sociais. É preciso recordar, com respeito a isso, como se disse, que "um mosaico de territórios é algo completamente diferente de um espaço organizado ao redor de um centro com uma periferia"(JOSEPH, 1988, p.24). Trata-se de uma cidade construída a partir de justaposições, resultado de uma ordem que responde tanto ao centralismo político como à concentração extrema da riqueza, ao desequilíbrio das migrações, ao crescimento demográfico desordenado e ao que se designa, nos termos do urbanismo governamental, uma "alta concentração de assentamentos irregulares". Os fluxos populacionais - e as políticas que os tornam possíveis - provocaram uma desarticulação crescente da sintaxe e dos ritmos urbanos que, como efeito de território, expressam-se finalmente na descentralização da vida urbana e em um resultado magnético de dispersão dos segmentos sociais. 
Ao mesmo ritmo em que os marginalizados de diferentes latitudes do país chegam ao centro, à capital do poder político e econômico, efetua-se um contínuo deslocamento das fronteiras urbanas para vilas e zonas rurais, o que, de maneira singular e sem dúvida muito sugestiva, os topógrafos aéreos passaram a chamar de expansão da mancha urbana.

Os resultados manifestam-se em estilos imprevisíveis de hibridização no melhor dos casos, quando não de segregação na maioria, econômica, social e, naturalmente, espacial. A multiplicação dos micromeios exigiria ter à disposição uma língua nova, a língua dos intervalos, que permitisse a avaliação das relações sociais atendendo às distâncias ${ }^{3}$. Os intervalos devem ser entendidos como distâncias de segregação e desenraizamento em nossos países. E, em uma diferente aproximação, como estados de estrangeirice para aqueles que não pertencem nem pertencerão, com as políticas neoliberais, à nova ordem internacional.

A cidade antiga dos palácios é hoje uma cidade sem centro que, não por acaso, manifesta-se em uma geografia deslocada e em deslocamentos recorrentes. O que fica do antigo esplendor - como espaço de congregação e localização - é o centro histórico, hoje espaço de mesclas - sociais, culturais durante o dia - e uma fantasmagoria noturna quando os turistas, os transeuntes e os funcionários locais desalojam o teatro colonial e pré-hispânico. Junto com o esvaziamento do centro, como enclave ordenador, orientador do território urbano, estendem-se, sem ordem nem controle, as periferias: o subúrbio como submundo da extrema pobreza e da extrema riqueza, espaço tanto dos marginalizados que habitam os chamados cinturões de miséria, como o lugar escolhido para os novos empreendimentos urbanos, onde imensos complexos comerciais e as torres de espelhos elevam um novo culto à acumulação material, seletiva e exclusiva da modernidade.

Os processos contraditórios de socialização e dessocialização - chaves para entender um processo de instabilidade permanente - não só produzem uma excentricidade exuberante na cidade, como ameaçam o mesmo espaço público e as identidades de grupos e indivíduos. Em certo sentido, todos somos imigrantes na Cidade do México. Assistimos a novas formas de desenraizamento e à lenta desarticulação de boa parte dos espaços tradicionais de encontro coletivo, espaços que não somente se ligavam a rituais públicos e gregários (festas de vizinhos, celebrações religiosas, intercâmbios coloquiais entre a vizinhança, compra e venda nos mercados, reunião nos parques, encontros em cantinas e cafés etc.) como constituíam a base de orientação e pertencimento das diferentes comunidades no território.

3 Sobre estes temas, consultar, por exemplo, o capítulo "Intervalo" mencionado de JOSEPH, Op. Cit.. 
De tal modo, poder-se-ia dizer que a cidade fragmenta-se em inumeráveis pontos, apenas sustentados por traçados viários que dão à paisagem uma idéia de continuidade e movimento. Parece que o espaço urbano converteu-se em lugar de trânsito e de passagem entre um lugar e outro, entre zonas de produção e localizações de vida cotidiana, entre um espaço de lazer e o regresso para casa. Talvez não seja exagerado dizer, em certo sentido, que os eixos viários, projetados como rotas velozes para o trânsito rápido, representam a metáfora mais expressiva da circulação da energia urbana: trata-se de chegar, não de se deter; de circular e não de passear ou perambular. Assim, a arte de deslocamento dos habitantes da capital é, no melhor dos casos, ir e vir por rotas pré-fixadas para lugares préfixados. A possibilidade de contato com a cidade e com os outros está a tal ponto restrita a rotinas fixas que a "liberdade de mobilizar-se", o "direito à cidade" e até o simples fato de conhecê-la - e habitá-la - reduzem-se dia a dia.

A dispersão urbana, que representa um novo estilo da dessocialização das práticas coletivas, não somente se expressa nos itinerários forçados e na superexploração do tempo de vida, como também nas representações e nos afetos dos que a habitam e Ihe dão sentido. Poder-se-ia dizer que a única cidade realmente existente como espaço urbano contínuo é a que aparece nos mapas de trânsito do Guía Roji, ou em algumas reportagens com vistas aéreas, e isso com muitas dificuldades. Dificilmente existe uma imagem global do território urbano nas práticas e representações cotidianas de seus habitantes. Estes não o conhecem. A cidade realmente habitada, para a maioria da população, é medida pelo intervalo existente entre os espaços de trabalho, o bairro onde se mora e alguns escassos lugares públicos de lazer; o resto são prolongamentos ou extensões, em geral conhecidas de oitiva ou pela televisão.

E essa é uma linguagem comum nas diversas representações de seus habitantes, que manifestam em seus relatos a intensificação das disciplinas da indiferença na Cidade do México, assim como dos lugares do anonimato e do vazio impessoal. Esses estilos de uso da cidade alcançam sua consumação com os traçados das redes audiovisuais, o lugar do não lugar, em que o rumor anônimo da rua ou do escritório é substituído por vozes anônimas ou personalizadas - conforme o caso - que, de qualquer modo, a partir dessas novas disciplinas da indiferença (ou da inércia), reclamam o enraizamento dos espectadores.

Dentro dessa perspectiva, quero sublinhar a idéia de que os meios, particularmente os audiovisuais, fazem parte dos equipamentos coletivos dos espaços urbanos. Embora com diferenças marcadas pela natureza de sua função social, cabe observar que, como qualquer outro equipamento (a fábrica, a escola, os bancos ou os hospitais, os centros comerciais ou os eixos viários), as tecnologias da imagem têm por objetivo produzir integração mas, ao mesmo tempo, tendem a uma distribuição do território, a produzir divisões e subdivisões no corpo social, a 
reorganizar o espaço e o tempo; em suma, a fixar tudo aquilo que é capaz de fluir. Como equipamento coletivo, a televisão e suas tecnologias representam uma codificação do corpo social: instituem uma maneira de diagramar os espaços coletivos, a vida íntima e a pública, o tempo livre e o tempo de trabalho. Nesse sentido, as novas tecnologias exibem uma tendência marcante a encerrar e a enquadrar os fluxos populacionais em determinados espaços e a fixar e regular os ritmos temporais da vida cotidiana. Esses equipamentos são uma espécie de híbridos sociais, espaços de interseção entre as esferas pública e privada. Submetidos a poderes fortemente centralizados são, ao mesmo tempo, suporte da vida doméstica e da privatização das práticas culturais.

Os novos regimes de visibilidade dos dispositivos audiovisuais instituem, como foi dito, sistemas que definem a habitabilidade dos espaços. Por isso, é possível falar de territórios televisivos, aqueles lugares em que as sociedades atuais passam a maior parte de seu tempo. Esses novos territórios formam um círculo sobre as sociedades íntimas - a família, as redes amplas de parentesco, os micromeios - enquanto iluminam com novos matizes as cenas de todos os dias. 0 objeto técnico - e suas projeções narrativas e simbólicas - muda nossa relação com o espaço e, neste ponto, cabe recordar o caráter móvel dos territórios audiovisuais, sua essência intimamente fragmentária, sua condição perecível que se implanta, precisamente, em espaços de extrema solidez como são os que compõem a vida cotidiana e as relações familiares, com sua perseverança ou sua relativa inércia.

Dentro desse panorama geral, tentarei uma aproximação, por certo fragmentária, a partir de diversos ângulos, a saber: a aparição do que chamarei de culturas sedentárias e pólos de inércia; em segundo lugar, o que se podem designar como culturas do esquecimento sobre a base de regimes de máxima visibilidade e, finalmente, uma abordagem dos gostos (e de certas "estéticas") como espaços de hierarquização e desigualdade. 


\section{Mediações (fragmentos)}

\section{Culturas sedentárias e pólos de inércia}

Há algum tempo, desenvolvo uma pesquisa de campo, de caráter etnográfico, sobre práticas culturais e vida urbana na Cidade do México ${ }^{4}$. Do traçado de estilos de vida que essas explorações permitiram vislumbrar, tomarei alguns dados para as observações seguintes. Essas informações também sustentaram boa parte das idéias da seção anterior.

Embora sejam de certa generalidade, os relatos que utilizarei aqui permitem estabelecer um marco relativamente consistente de hipóteses sobre os novos estilos de vida urbana na Cidade do México no chamado "tempo livre", particularmente no que se refere ao consumo cultural. Por razões de espaço, os relatos não aparecem até o final - nas vozes de seus protagonistas, mas subjazem, como substrato de inteligibilidade, em todas as idéias que estou expondo ${ }^{5}$. Como foi possível notar, sobretudo nos setores populares, surge com alguma nitidez uma tendência mais ou menos generalizada para atitudes de refúgio na intimidade doméstica. São os segmentos mais despossuídos da população que se refugiam nesses âmbitos por razões que, embora heterogêneas, respondem a situações parecidas de privação e marginalidade: jornadas extenuantes de trabalho, salários ou rendas exíguas, baixos níveis de escolaridade, desorientação perante os traçados urbanos, estranheza diante dos bens da cultura superior e dos equipamentos culturais públicos e, sobretudo, uma passagem difícil de estilos pré-modernos de vida (a maioria das famílias entrevistadas procede, em primeira ou segunda geração, de outros estados do país, de zonas rurais ou semi-rurais) para as incitações da modernidade urbana.

Nessa espécie de pausado declínio da vida pública que se conecta de algum modo com o ocaso de estilos tradicionais de convivência em vias de diluir-se no anonimato da grande cidade, as tecnologias de comunicação à distância cumprem um papel relevante. Não é exagero dizer que as novas culturas audiovisuais, como dispositivos de múltiplas redes, redefinem em larga medida os traçados modernos de conexão com o mundo a partir da intimidade da casa. Assim como os equipamentos culturais públicos tendem a um declínio mais ou menos irreversível, as auto-estradas da comunicação - espaços onde se manifestam as dimensões econômicas, estéticas e lúdicas da sociabilidade coletiva - começam a converter-se,

\footnotetext{
$4 \mathrm{O}$ estudo de campo consistiu, em traços largos, em observações diretas e entrevistas em profundidade de vinte famílias, a maioria de setores populares e, como contraste, algumas de setores médios. Ao mesmo tempo, selecionaram-se unidades que viviam em diferentes pontos da cidade e também se considerou a pirâmide geracional no núcleo familiar, entre 60 e 18 anos aproximadamente. Em circunstâncias em que foi possível, também se incorporou ao estudo a população infantil.
}

5 Segundo indicam as últimas cifras do Banco Mundial, esses setores representam $85 \%$ da população urbana que oscilam entre a pobreza e a pobreza extrema ("BM: se extingue la clase media mexicana". Jornada, México, 4238, 24 jun. 1996). 
de maneira crescente, em lugares diferenciais de consagração, reafirmação ou simplesmente sobrevivência, social e simbólica, de diversos segmentos da população.

É sabido que, em relação à cultura, e me refiro em particular aos países latino-americanos, assistimos a um lento ocaso da tradição do livro; os grandes cinemas dão lugar a salas pequenas nos centros comerciais; os museus, os teatros, as salas de concerto convertem-se em espetáculos oficiais que renovam velhas glórias do passado. As culturas populares, por sua vez, sobretudo nas grandes urbes, mudam seus estilos de existência e adaptam-se aos novos ritmos da vertigem tecnológica. O que parece evidente, em um e outro caso, é uma política de redistribuição dos bens culturais, que reafirma as hierarquias de classe e poder entre a população, bem como as distâncias e a desigualdade nos mapas sociais. As minorias, de diferentes classes, continuam mantendo o privilégio de sê-lo em relação ao gosto que desenvolvem pela cultura escrita, os museus e as últimas expressões cinematográficas ou musicais, as redes informáticas e as autopistas da comunicação. Paralelamente, o resto dos grupos sociais, os que pertencem à base da pirâmide (sem exagerar, aqueles que teriam de ser, nas dimensões imaginárias da política, os destinatários do sonho da revolução tecnológica, a chamada modernização) vivem em um estado que flutua entre o ceticismo (ou a desesperança) e o alarme, a passagem da pré-modernidade e das tradições de origem para os novos estímulos das culturas urbanas.

Em nossos países, a ilusão de comunidade, fundada, em boa medida, nas redes audiovisuais como vínculo com os "outros", não somente significa, às vezes, a renúncia a espaços coletivos de convivência como também a emergência de novos estilos da cultura da pobreza. É a cultura que se estende dia a dia, desde o imaginário audiovisual, sobre as comunidades marginalizadas das diversas ordens da vida coletiva. E com isso me refiro não somente a práticas específicas da maioria da população - os públicos cativos que se integram fluidamente, perante a inexistência de alternativas reais, a circuitos culturais centralizados que comandam o que é preciso ver e ouvir, como também à pobreza da cultura tal como circula na programação de quase todos os canais privados de televisão, bem como nos sistemas de cabo e finalmente nas ofertas das videolocadoras, grandes armazéns de filmes freqüentemente intercambiáveis, anônimos, descartáveis, que atualizam uma espécie de degradação da linguagem e dos símbolos coletivos.

Este é um ponto de inflexão das culturas contemporâneas, que representa novas modalidades de manifestação e concentração do poder e o surgimento, quase em linha paralela, de modernos estilos de vida. Trata-se de uma política, mas também uma estética e uma ética de final de século. Diz-se com freqüência que, na atualidade, os grandes centros de poder e decisão das sociedades estão estreitamente vinculados ao controle da informação e das redes eletrônicas. Saber e 
poder, talvez de uma maneira inédita nos processos históricos, estão hoje inextricavelmente associados. Mas o poder estende-se, gradualmente, com base em enclaves que fortalecem de maneira crescente o que Paul Virilio denomina "pólos de inércia". O instante privilegiado substitui a extensão do espaço ou, de outro modo, contrai o território, favorecendo o deslocamento em um mesmo lugar: este é o objetivo dos veículos audiovisuais que instauram a inércia nos espaços privados e instituem o triunfo de "culturas sedentárias que estabelecem o predomínio do tempo sobre o espaço: a mobilidade sem deslocamentos"(VIRILIO, 1990, p.37ss).

Este mesmo autor sustenta ainda que passamos do tempo extensivo da história ao tempo intensivo de uma instantaneidade sem história, a partir das tecnologias do momento e das técnicas da velocidade dos transportes, das redes audiovisuais e da informática. Ele formula a metáfora desta tensão da vertigem e da contração das durações com uma simples pergunta: como ir para lugar nenhum, sempre menos distante, mas sempre com mais velocidade?

O que está em questão, dirão de sua parte os sociólogos dos micromeios que medem e avaliam os intervalos que regulam a interação urbana, é a unidade dialética de distância e proximidade, constitutiva de toda relação social ${ }^{6}$. O que está em questão, para dizê-lo de outra maneira, é o recuo dos cidadãos para a vida privada, a desmobilização progressiva que permite pôr uma certa distância para com a esfera do público ou, ao menos, conectar-se, de um modo radicalmente diferente, com os assuntos da comunidade.

O estreitamento do espaço público não somente conduziria a uma crise do mesmo espírito do urbano, como também a uma espécie de despolitização dos costumes, à desagregação dos laços de solidariedade que, em muitos casos, não transcendem os laços de parentesco, ao mesmo tempo em que cambaleiam algumas das chaves que asseguram os princípios de identidade, como por exemplo, aquelas que definem a comunidade como um grupo social composto por membros que acreditam compartilhar algo. Hoje, "compartilhar algo" tem outras dimensões que, em geral, estão relacionadas com um âmbito comum, o das redes audiovisuais e seus relatos sem fechamento.

\footnotetext{
${ }^{6}$ A propósito desses temas pode-se consultar o capítulo "Intervalos", já citado, de JOSEPH, Op. Cit.
} 


\section{Regimes de visibilidade e culturas do esquecimento}

Diz-se, com certa freqüência, que os saberes contemporâneos tendem a transformar-se em um reflexo: o espelhismo sempre renovado da ilusão cinemática. Desse modo, a repetição de informação já conhecida perturbará cada vez mais os estímulos da observação, extraindo-os automática e rapidamente não somente da memória mas, sobretudo, do olhar, até o ponto em que, a partir de então, a velocidade da luz limitará a leitura da informação e o mais importante na eletrônica informática será o que se apresenta na tela e não o que se guarda na memória (VIRILIO, 1988, p.60-61)

Com a revolução das telecomunicações, enfrentamos 0 ideal da transparência: se tudo é visível, nada escapa ao controle do olhar, ou seja, a um certo saber do que acontece sob esta vigilância, o que nos leva a imaginar a abolição do segredo nas culturas analógicas: vemos o que é e a realidade é isso que vemos. Ou, dito de outro modo, o mundo aparenta estar à nossa disposição, a informação parece ser instantânea, ao mesmo tempo em que experimentamos a sensação de uma certa onipotência sobre o que acontece fora de nossas fronteiras individuais, ou seja, uma nova noção do controle e do poder sobre o entorno, contra o desamparo ou o não saber.

A imagem torna-se penhor do verdadeiro: ver para crer e, simultaneamente, a renovação dos laços sociais nessas comunidades imaginárias. A visibilidade de certos cenários, multiplicada pela transmissão direta, tende a produzir um efeito de participação à distância que purifica os temores essenciais, entre outros, o contato como fantasia de contaminação; permite, do mesmo modo, despojar o corpo na mesma medida em que o Outro se converte - pelo menos nos atalhos imaginários em espécie em vias de extinção e a imagem em imagem de si mesma. Para Debray, nas nossas culturas prevalecem os olhares sem sujeito na mesma proporção em que nossas imagens diminuem, gradualmente, sua dependência da realidade exterior. O visual procura certezas (DEBRAY, 1994, p.254ss).

$\mathrm{Na}$ época da cultura do visual, parece que somente o visível é objeto de credibilidade, com o acréscimo do que a afirmação anterior nos sugere como conseqüência ou, pelo menos, como probabilidade que emerge dos novos campos culturais. De tal modo, poderíamos agregar, somente o que se vê (o que fica registrado nos novos campos de visibilidade) se pode esquecer porque os registros da memória já não são os da memória interior, mas os que se guardam na repetição de imagens sempre renovadas, um presente absoluto, na televisão ou nos arquivos eletrônicos da computação. Essas culturas da máxima visibilidade são culturas do esquecimento?

\footnotetext{
${ }^{7}$ Os grifos são meus.
} 
É o que parecem sustentar alguns pesquisadores quando estabelecem a distinção (que não é senão uma oposição) entre "sociedades com memória" (cujo referente é a história lenta como longa duração e densidade cultural) e "sociedades sem memória" (cujo referente seria a comunicação e seu paradigma, a publicidade, o efeito de realidade construído sobre a curta duração)"8. O que se suprime é a percepção da duração e, por conseguinte, a temporalidade histórica. Tratam-se de culturas efêmeras ou, como alguns preferem chamá-las, de culturas frágeis, projetadas para sustentar sua indeclinável caducidade. Há muitos anos, Jameson (1988) já havia alertado para esses aspectos, quando afirmou que a lógica profunda do capitalismo multinacional radicava no desaparecimento de um sentido da história, na medida em que todo o sistema social contemporâneo, em suas diversas manifestações, começava a perder gradualmente sua capacidade de reter seu próprio passado, vivendo em um presente constante e em uma constante mudança que arrasa tradições de classe, que todas as anteriores formações sociais tiveram de preservar de um modo ou de outro.

É preciso acrescentar que os discursos televisivos caracterizam-se pela ausência de fechamento ou, pelo menos, pela intenção de negar toda forma de fechamento, o que representa uma propensão a prolongar-se até o infinito (REQUENA, 1988). Esse discurso sem limites, sem começo nem fim porque é de uma fluência ininterrupta - o macrodiscurso televisivo, como o chama uma corrente da semiótica -, apresenta, por essas características, um isomorfismo com as rotinas da vida cotidiana. É um jogo de espelhos em que se jogam as tarefas sem fim, os afazeres que uma vez resolvidos começam novamente pelo princípio e encontram um atenuante nessa projeção das imagens. Também são os efeitos de deslocamento, a fuga do sentido, esse estado de deriva das imagens, o que permite pôr sob um cone de luz a própria condição efêmera, perecível das tarefas domésticas, onde a fluidez - das imagens, dos afazeres - vai no sentido contrário ao da acumulação.

Em relação às proposições anteriores, caberia fazer uma série de perguntas. Em primeiro lugar, a questão é saber se existe uma reapropriação imaginária das representações televisivas ou se existe, dadas as atuais condições de vida dos setores populares, uma certa criatividade nas táticas dos usuários para elaborar leituras e respostas diante da proliferação das mensagens audiovisuais. Numa segunda ordem de idéias, trata-se de analisar o efeito de desterritorialização que as culturas da imagem podem causar nos destinatários. A aparente multiplicidade das mensagens audiovisuais favorece a abertura a outros mundos, que habitualmente designam-se como os da globalização? Assistimos à possibilidade de viver

\footnotetext{
${ }^{8}$ Estes temas são propostos por MONS (1994). Ver, em particular, o capítulo "El alunizaje del bicentenario", p. 93 ss.
} 
experiências multiculturais, polifonias e sincretismos, diante dessas redes que supostamente projetam diferentes códigos simbólicos e registros culturais?

Se existe uma reapropriação dos bens multiculturais da pós-modernidade por parte dos setores populares, em que termos ocorre essa reapropriação? As identidades se renovam e se transformam nos novos cenários comunicacionais, em que se apagam as fronteiras territoriais e simbólicas? É possível falar de culturas híbridas (para todos)? E, em caso positivo, é possível definir sujeitos que podem transcender os limites e as limitações urbanas e os das culturas da pobreza para inscrever-se na ordem da hibridação de estilos de vida, formações simbólicas, rituais da ordem cotidiana? Voltarei a essas questões.

De imediato, tenho a impressão, a partir da experiência de campo, de que os meios audiovisuais, através de uma sintaxe rotineira e de recursos discursivos próprios de culturas efêmeras que pretendem promover sempre efeitos de realidade, próximos, familiares, íntimos, favorecem uma fixação profunda em um repertório de saberes consagrados e em resíduos de ideologias que fazem parte do sentido comum e das idéias dominantes em certos setores urbanos. Se a arte é uma forma de choque, como diz Walter Benjamin, e não pode senão cultivar, como próprio de sua natureza profunda, uma situação de estranhamento ou desenraizamento, os relatos efêmeros produzidos para o esquecimento, fundidos nos diversos mecanismos de verossimilhança, têm ou teriam o objetivo oposto, qual seja, arraigar a percepção e a visão a estados de certa continuidade com o já conhecido (isto é, o registro do "normal", do aceitável, que induz à crença em uma certa estabilidade das coisas e do mundo).

Nesse sentido, é possível reconhecer, em primeira instância, que a vida familiar, o enclave das redes audiovisuais nos espaços íntimos tem, segundo indicam as observações de campo, um efeito de território sobre o traçado de uma narrabilidade que, embora contínua, é quase sempre fragmentária, impondo pelo próprio curso das rotinas cotidianas uma determinada orientação à possível dispersão das mensagens. Ademais, a fixação nesse centro magnético que é a família (e o familiar, por extensão) pode causar uma mutação sobre os efeitos desterritorializados de outros mundos, porque essa visão planetária que tem lugar em um não-lugar desdobra-se (e redobra) sobre um horizonte estável de ideologias, fragmentos de saberes, opiniões de uso cotidiano, sentido comum ou, se se quiser, a moral corrente em estado prático dentro desses segmentos de espectadores.

Já há muito tempo, Roland Barthes tentou marcar a enorme diferença entre cinema e televisão, a qual aludia como a domesticação que finalmente penetrava nas esferas da intimidade, destruindo os estados hipnóticos da fantasia (BARTHES, 1986). No cinema, escreveu Metz (1979), a participação afetiva pode ser particularmente viva, conforme a ficção do filme, conforme a personalidade do espectador, mas como mediadora desses matizes e, no melhor dos casos, 
manifesta-se em certo grau a "transferência perceptiva", durante breves instantes de fugaz intensidade:

"A consciência do sujeito é radicalmente diferente na contemplação televisiva; os estados de transferência são mais que fugazes e sofrem a interferência, são bloqueados, por uma escuta que a cada momento cede lugar a uma interrupção doméstica. Já não se trata de intensidades: nos referimos a existência de rotinas fixas, do encontro e reencontro com o mesmo, da necessidade de confirmar, na maioria dos casos, certezas elementares" (METZ, Op. Cit., p.91).

Falei, em páginas anteriores, de pólos de inércia para situar uma modalidade de vida e de escuta que parece, por momentos, não somente remeter ao esquecimento como também, poder-se-ia acrescentar, a um tipo de seletividade pouco reflexiva. A maioria das experiências de campo parece sugerir uma espécie de entrega voluntária, e às vezes relativamente inconsciente, dos espectadores ao que se oferece. Os pólos ou estados de inércia adquirem outra ressonância se os colocamos sob o novo prisma. Não se trata, nesse caso, de uma sala de cinema escura, anônima e silenciosa que situa a experiência da decifração e o gozo estético: ao contrário, a escuta e a visão são regidas pelo próprio centro de equilíbrio e regulação das energias afetivas e morais da família. É lugar de certezas que se restabelecem cada vez perante os gestos - e os rituais - repetidos e conhecidos da convivência e que traçam uma continuidade sem sobressaltos. A hipnose não ocorre; a identificação e a projeção acontecem dentro de outros registros. Sempre existe a possibilidade de recorrer à ancoragem no conhecido: a casa, a família, os objetos de uso corrente. Pode-se falar então de atos, no sentido que Ihe dá Metz: o de uma entrega, uma descarga motriz que permanece sob controle (METZ, Op. Cit., p.92).

Os gostos: espaços de hierarquização e desigualdade

Creio que as cenas multiculturais das cidades periféricas, em particular, podem ser concebidas como efeito de conjunto e da enorme superposição de geologias simbólicas que manifestam-se nos novos espaços sem fronteiras. É menos convincente pensar o multiculturalismo como próprio de todos os setores sociais ou o conjunto multinacional como uma montagem de traços que qualquer cidadão de qualquer país, etnia, sexo, religião ou ideologia pode ler e usar (CANCLINI, 1995, p.16). Como o próprio Canclini reconhece - pondo o acento nos conflitos derivados da globalização -, o mercado, ao reorganizar a produção e o consumo para obter maiores lucros e concentrá-los, converte as diferenças 
nacionais, embora não homogeneizadas pelo pólo transnacional, em desigualdades (CANCLINI, Op. Cit., p.18).

Neste ponto, parece-me necessário voltar a algumas das categorias que Bourdieu (1988) cunhou sobre a distinção para entender os estilos de vida e os gostos dos diferentes setores sociais. Não ignoro que Bourdieu foi fortemente criticado, sobretudo por estudiosos da América Latina, no que se refere à sua maneira de conceber as práticas, os usos e costumes dos setores populares. Algumas dessas críticas são pertinentes, posto que nossos países de fortes contrastes culturais exibem ainda a imensa capacidade de suas comunidades particularmente das que ainda não foram conquistadas pela urbanização selvagem - de reinventar, a partir de tradições profundas, novos estilos de criar e viver as experiências estéticas, lúdicas e rituais, reincorporando elementos da modernidade. No entanto, creio que, na atualidade, é de toda pertinência voltar a algumas das proposições de Bourdieu para entender as experiências de vida, o uso do tempo e do espaço, as práticas cotidianas e os gostos de amplos setores entre marginais e integrados dos espaços urbanos. Refiro-me, naturalmente, às maiorias silenciosas, aos indivíduos da rua, que vivem amarrados às rotinas cotidianas, em especial às rotinas de sobrevivência, espaços das histórias menores, aquelas que apenas deixam traços em face dos grandes episódios da vida social.

$\mathrm{Na}$ pesquisa que citei anteriormente, os resultados de numerosas entrevistas e práticas de observação parecem confirmar, na maioria das dimensões da vida cotidiana, o que poderíamos designar como a presença generalizada das culturas da privação. Com escassos matizes de diferença, encontramos na maioria das famílias entrevistadas uma espécie de afinidade de estilo (BOURDIEU, Op. Cit. , p.172) em que umas e outras podem reconhecer-se como no espelho. As variações não são significativas, antes ratificam a repetição obrigada de certas práticas que excluem, às vezes, a possibilidade de uma escolha crítica e racional. Porque, e nisso concordo com Bourdieu, se os estilos de vida e os gostos, como categorias tipicamente burguesas, supõem uma liberdade de escolha, como conceber então o gosto por necessidade, aquele que é o resultado da privação da possibilidade aberta de escolhas?

"Fazer da necessidade virtude", diz-se com freqüência; em termos mexicanos, a tradução seria: "do perdido o que apareça". Sugeri antes a existência de servidões; talvez fosse melhor falar de cativeiro: aqueles que, cativos no lugar a que pertencem (em termos reais, ao que foram reduzidos), estão condenados a ser escravizados pelas mensagens efêmeras que caem do céu e povoam de algum modo as fronteiras, cada dia mais estreitas, dos que estão fora de toda possibilidade de escolher. "Eu ando sempre mudando e mudando, passeio por toda a televisão até que encontro algo... Quer dizer, não estou vendo uma coisa, estou mudando, ponho um canal e fico vendo o que tem...", conta uma das entrevistadas. 
Sobreviver. Como sobrevivem os marginalizados, que representam quase a maioria da população de nossos países ? Essa é a única realidade com base na qual se pode pensar a cultura (ou será preciso escrever $A$ Cultura?), uma rede de privilégios que, ao definir o gosto, está também definindo - junto com as hierarquias que separam e asseguram as diferenças entre os que detêm o poder e os que não o têm - os horizontes de vida da maioria da população. O que significa dizer, para não entrar nos dados duros e decisivos da economia: a vida com algum sentido, a fantasia, os sonhos, a ficção, a sociabilidade entre os indivíduos. Há um gosto pelas coisas de primeira necessidade? Quais são as necessidades primeiras? As que têm prioridade? Não é preciso dar respostas. Seria preciso perguntar como se vive em um espaço que se estreita dia a dia, no qual é necessário dar respostas somente de primeira necessidade.

"O gosto", escreve Bourdieu em relação aos setores populares, "é amor fati, escolha do destino, mas uma escolha forçada, produzida por certas condições de existência que, ao excluir como puro sonho qualquer outra possível, não deixa outra opção senão o gosto do necessário" (BOURDIEU, Op. Cit., p.177, destaque do autor, grifos meus). "Não vou querer aquilo que não posso ter", costuma-se pensar, dizer ou sentir; as versões são variadas: "quero aquilo que posso ter"; e mais: "me contento com o que tenho, não? para começar, que tenhamos para viver, poder educar os filhos, ter saúde", explica Pedro. Poder viver ao menor custo, isto é, sobreviver. "Vou te dizer uma coisa", conta Chela, "quase não gosto de andar muito assim de passeio... então quase não saio... Como toda a semana ando, seja lavando, passando, tirando os passarinhos, então, para mim, sábado e domingo são dias de descanso, deixo que os meninos façam o que quiserem e como tem filmes aos domingos na televisão, então me deito e fico vendo a tevê". As culturas da privação ou, como antes quis designá-las, as culturas da pobreza, não somente marcam a fogo e excluem os praticantes de quase toda e qualquer esperança; estão aí - como a violência inerte das coisas - e permanecerão nos termos que sociedades cada dia mais injustas decidirem sua existência, ou até que os "desiguais" possam decidir mudar os termos da desigualdade.

O gosto por necessidade, pensa Bourdieu, apenas pode engendrar um estilo de vida em si, que só pode ser definido negativamente pela relação de privação que mantém com os demais estilos de vida (BOURDIEU, Op. Cit., p.178). Emblemas eletivos ou estigmas... À falta de capitais culturais (mas também, como é óbvio, econômicos e sociais), à força de viver à margem de uma cidade que devora a si mesma e que marginaliza a maioria, os gostos convertem-se nessa condenação (ou em destino?) de que falamos antes. O universo povoa-se de alguns dados que são significativos para compreender as práticas dos marginalizados: "do tempo livre nem me fale"; "o que é o tempo livre?"; "eu, descansar não descanso nunca, ando no corre e corre todos os dias...", "que te digo, sempre encontro algo para fazer, eu não me encontro 
se não tenho algo entre as mãos..." O que em inglês se denomina sense of one's place. Poderíamos falar, se queremos designar com maior propriedade esta situação, da existência de um tempo intersticial, que se resgata com diferentes táticas entre os intervalos que separam as múltiplas atividades de reprodução e sobrevivência. Esses tempos intersticiais não se manifestam somente nos espaços cotidianos da jornada semanal. Instalam-se, de maneira decisiva, em todos os espaços de vida, inclusive nos fins de semana. "Programas que te possa dizer que vejo diariamente. Diariamente, em pedaços não? ..." - diz Verônica. Algo similar contam as demais entrevistadas: "que eu fique mil horas vendo televisão, isso não; vejo um pouquinho e no anúncio saio rápido e volto..."

Nesse ponto, é importante destacar que a amplitude pluricultural de sociedades como a mexicana pode exibir traços extremos de criatividade em regiões que de algum modo estão relativamente distantes do urbano como sistema operatório que coloniza mentalidades e culturas sedimentadas. Os habitantes dos espaços urbanos, muitos deles desenraizados de seu território de origem, mas ao mesmo tempo das culturas sobre as quais edificaram princípios de pertencimento e identidade, parecem demonstrar algumas das teses de Bourdieu e o que chamei, apelando para uma velha designação antropológica, de a presença da "cultura da pobreza". Em numerosos casos ocorreu um salto, que é realmente uma fratura de proporções, entre as culturas de origem, particularmente camponesas com características pré-modernas, às vezes orais, e as culturas e técnicas da velocidade que representam um estágio qualitativamente diferente nos ordenamentos simbólicos da época.

Esse salto cultural parece manifestar-se como um processo de paulatino empobrecimento de certos códigos vitais e simbólicos e, de algum modo, é conseqüência dos meios de comunicação, isto é, da imposição de uma regularidade de formas materiais e discursivas que tendem a suprimir a possibilidade da distinção (de distinguir valores e hierarquias como exercício de reconhecimento de bens culturais "legítimos", ou ainda os chamados populares, que exigem, uns e outros, uma recriação crítica e uma elaboração permanente). Desse modo, ocorreria uma dupla perda que se manifesta no que se poderia chamar de uma fratura, quase sem mediações, da oralidade primária à oralidade secundária: a passagem dos relatos orais das comunidades, que desse modo se reconhecem e perduram por esse reconhecimento, à oralidade audiovisual ${ }^{9}$, que em muitos casos pode ser traduzida - em um país com altos índices de analfabetismo real ou funcional - em uma adesão acrítica ou com escassas perspectivas de leitura das mensagens da insignificância. E se quiséssemos estender ainda mais esta idéia, o que prevalece, a meu juízo, é a aceitação - por necessidade ou por privação - das

\footnotetext{
${ }^{9}$ Sobre estes temas pode-se consultar ONG (1987).
} 
regras de uma cultura em que se manifesta, sem termos atenuantes, o predomínio da fórmula sobre a forma, os rituais da repetição, uma fala coagulada que parece falar a todos para despojar de sentido aquilo que se chama ou que se poderia chamar de os sentimentos de uma comunidade: o grau zero da cultura, como poderíamos dizer parafraseando Barthes.

A isso é preciso acrescentar que os estados de empobrecimento cultural que essas redes propiciam na maioria dos casos não somente suscitam paixões cotidianas e absorventes, como não têm contrapesos em outras práticas culturais. Não há seletividade nessa entrega, que prefere o existente ao nada ou ao vazio, ao mesmo tempo em que se desvanecem dia a dia as relações de sociabilidade urbana, as formas interpessoais de contato e, em muitos casos, os níveis de politização das massas, de organização e de encontros coletivos. Isto é, a possibilidade do diálogo, a luta comum, certas redes de solidariedade, a abertura ao mundo e aos assuntos comuns, ou seja, o que comunica e amplia os horizontes de visibilidade e enunciação de uma comunidade.

E, para voltar ao começo desta seção, caberia retomar certas perguntas: pode-se falar, nesses casos, de disposições do gosto para certas experiências lúdicas ou estéticas, para certas formas da ficção ou das narrações televisivas, ou simplesmente nos encontramos com uma rede de determinações que fazem da disposição uma imposição? A pergunta valeria por um duplo motivo, o primeiro, porque na maioria dessas situações não há liberdade de escolha; o segundo, porque as culturas de nossos tempos têm a capacidade - sobretudo nos meios audiovisuais - de saturar todos os espaços da experiência e do desejo por meio de uma narratividade incessante que responde basicamente às estéticas da repetição.

Nesses aspectos, torna-se necessário, quase imprescindível, fazer uma história das relações de poder nestas esferas. E, em particular, em nossos países. Se, como ocorre, a maioria da população vive submersa na história de relatos anódinos, em um sonho que é provavelmente o único que não lhes dá pânico sonhar - sobretudo se se trata dos sonhos dos marginalizados ou dos que são objeto conseqüente, cotidiano, de marginalização - de que modo estudar essas culturas da pobreza sem "incorrer" no que os especialistas do campo estigmatizaram como uma visão simplificada do poder? Creio que os estudos da vida cotidiana permitem distinguir poderes insidiosos que penetram por todos os resquícios e se convertem em estilos de vida, como jogo de cumplicidades em que o poder é transfigurado em prazer ou em pequenas compensações diante da privação. Mas também é certo que, se aceitamos que o poder do mago radica na crença coletiva nas propriedades da magia, os abusos do poder somente podem ser sustentados se aqueles, como nós, em condições de vê-los, não contribuirmos para desmontar seus mecanismos. 


\section{Bibliografia}

BARTHES, Roland. Lo obvio e lo obtuso. Imágenes, gestos, voces. Espanha: Paidós Comunicación, 1986.

BOURDIEU, Pierre. La distinción. Criterios y bases sociales del gosto. Madri: Taurus, 1988.

CANCLINI, Nestor Garcia. Consumidores y ciudadanos. Conflictos multiculturales de la globalización. México: Grijalbo, 1995.

DEBRAY, Regis. Vida y muerte de la imagen. Historia de la mirada em Occidente. Espanha: Paidós, 1994.

JAMESON, Frederic. Posmodernismo y sociedad de consumo. In HAL FOSTER, HABERMAS, J. et al. (orgs.). La Posmodernidad. México: Kairós, 1988.

JOSEPH, Isaac. El transeúnte y el espacio urbano. Barcelona: Gedisa, 1988.

METZ, Christian. El significante imaginario. Barcelona: Anagrama, 1979.

MONS, Alain. La metáfora social - Imagen, territorio, comunicación. Buenos Aires: Nueva Visión, 1994.

ONG, Walter. Oralidad y escritura. Tecnologías de la palabra. México: Fondo de Cultura Económica, 1987.

REQUENA, Jesús González. El discurso televisivo. Espetáculo de la posmodernidad. Espanha: Cátedra, 1988.

ROMAN, Joel. La ville: chronique d'une mort annoncée?. Esprit, Paris, jun.1994.

VIRILIO, Paul. Estética de la desaparición. Barcelona: Anagrama, 1988.

EL último vehículo. In ANCESCHI; BAUDRILLARD et al. (orgs.) Videoculturas de fin de siglo. Madri: Cátedra, 1990.

WARD, Peter. México: uma megaciudad. México: Consejo Nacional para la Cultura y Artes, Alianza Editorial, 1990.

Tradução e publicação autorizadas pela FLACSO - México do artigo "Acerca de la Comunicación em Las Grandes Ciudades". Perfiles Latinoamericanos - Revista de La Sede Académica de México de la Facultad Latinoamericana de Ciencias Sociales, ano 5, n`9, dez/96. 